\title{
Los baños de Carlos III en Trillo. La extensión de la hidroterapia
}

Carlos III's baths in Trillo. The extension of hydrotherapy

\author{
Alet V ALERO \\ Centro de Estudios Ibéricos e Iberoamericanos (CEIIBA, EA 7412) \\ Universidad de Toulouse-Jean Jaurès
}

CESXVIII, núm. 30 (2020), págs. 609-634 DOI: https://doi.org/10.17811/cesxviii.30.2020.609-634 ISSN: 1131-9879
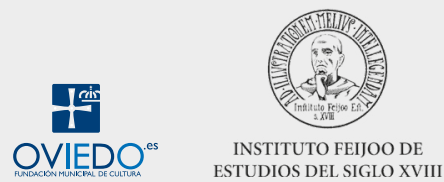


\section{RESUMEN}

Con el Real Decreto de 29 de junio de 1816 Fernando VII creaba el Cuerpo de Médicos de Baños. Se ha investigado la historia de este cuerpo y de la hidrología médica en España desde 1816. Los trabajos sobre el periodo anterior no parecen haber prosperado tanto y la iniciativa de Fernando VII pudo aparecer como un «arrebato legislativo». Tomando el caso de los baños de Trillo o «baños de Carlos III», se cuestiona este aspecto. Este caso permite ver en qué consistían las instalaciones de baños en torno a 1780, las obras realizadas, el reglamento y uso de las aguas, los conocimientos en cuanto a su composición y remedios para definidos achaques. También se entiende cómo se siguen estos puntos de desarrollo desde el Gobierno mediante el Consejo de Castilla lo cual, posiblemente, permite comprender mejor cómo esta situación prepara el Real Decreto de 29 de junio de 1816.

Palabras clave

Siglo XVIII, España, hidroterapia, Carlos III, Trillo.

\section{ABSTRACT}

With the Royal Decree of the $29^{\text {th }}$ of June 1816 Ferdinand VII founded the Corps of Doctors of Baths. Studies have concentrated on the evolution of this Corps and medical hydrology in Spain since 1816. But works on the prior period do not abound and it is generally believed that the king's initiative had been a «legislative caprice». This is what we want to question as regards the «fields of knowledge» related to cures, medicine and hydrotherapy. The baths at Trillo are also known as the «Carlos III baths». This site allows to apprehend bathing facilities around 1780, the construction undergone, the baths and the waters rules of use as well as ideas as regards their composition and the cures that they provided for particular pathologies. This study also emphasizes questions regarding management in these establishments dependent on the Government through the Council of Castile. All of the above elements seek to show how these diverse elements paved the way for the legislation of the 1816 Decree.

KeY Words

18th century, Spain, hydrotherapy, Carlos III, Trillo.

Recibido: 16 de enero de 2020. Aceptado: 22 de mayo de 2020. 
Este trabajo se enmarca en una reflexión antropológica a partir de la relación especie humana-movilidad. De manera más reducida se enmarca en el campo de la antropología cultural basada en las modalidades y representaciones de dicha relación. Siguiendo un método destinado a poner de realce «genealogías de las sensaciones» ${ }^{1}$ Alain Corbin mostró de manera brillante que era pertinente la fecha de 1750 para dar cuenta de una nueva relación de las sociedades occidentales con el mar. El ritual médico del baño de olas marca la aplicación de las teorías médicas inglesas y el nacimiento de la hidroterapia ${ }^{2}$ marina en un intento que me atrevo a calificar, sin legitimidad médica alguna, de pre-científica.

En 1750, Richard Russell (1687-1759) publica en latín un tratado sobre los efectos del agua de mar sobre los ganglios linfáticos que se vulgariza y conoce un éxito que pasa las fronteras bajo el título de Dissertation on the Use of Sea Water in the Affections of the Glands. Sus teorías y el gabinete que instaló en Brighton lanzaron la práctica de los baños de olas hasta convertir rápidamente la ciudad litoral en bathing resort creándose entre la gentry un conglomerado de preocupaciones higienistas y salutíferas, de actividades distinguidas y de comportamientos asociados a la fashion. Este concepto socialmente productivo y potente se extendió a partir del litoral inglés hacia los litorales fríos de toda Europa occidental. En Francia, Hugues Maret (1726-1786) amplió los trabajos de Russell como lo muestra Alain Corbin. En el momento de mi tesis ${ }^{3}$, busqué equivalentes susceptibles de propagar en España las teorías russellianas y maretistas. Encontré rituales de baños a la ola a partir de 1830 en España pero no encontré las teorías doctorales y/o médicas correspondientes, ni para principios del siglo XIX ni para el siglo XVIII, que pudiesen coincidir con Russell o Maret. Hubiera podido concluir con el retraso de España. Pero signos contrarios se obstinaban. Primero para indicar que la tradición bañista existía en España y luego que el final del siglo XVIII aportaba cambios significativos que preparaban profundas evoluciones al igual que los países vecinos. En mi marco cronológico,

\footnotetext{
1 Alain Corbin, Le territoire du vide. L'Occident et le désir de rivage (1750-1840), Aubier, 1988.

2 Pedro María Rubio, Tratado completo de las fuentes minerales de España, Madrid, 1853.

3 Alet Valero, Oriente, playas y castillos. Pratiques, images et politiques touristiques en Espagne (1830-1928), tesis, Aix-en-provence, 1993, capítulo III, Pathologie et voyage, págs. 143-177.
} 
el médico que proponía una reflexión amplia sobre el sector hidromineral era el Dr. Rubio en su Tratado completo de las fuentes minerales de España, publicado en 1853. Como lo indica el título, el Dr. Rubio compilaba únicamente las fuentes minerales, pero reunía unos resultados muy anteriores que revelaban una tradición española de recursos y usos hidrominerales capaz de extenderse. El paso de las aguas minerales a las aguas de mar ha sido estudiado. Como lo demostró Michel Chadefaud en su tesis magistral Aux origines du tourisme dans les Pays de l'Adour ${ }^{4}$, bañistas y agüistas o se confunden o se completan o alternan en los balnearios y bathing resort en función de la temporada y de los rituales complejos que médicos y empresarios de baños difunden para atraer a la concurrencia. Parte de mi tesis procuraba reunir elementos en ese sentido. En la justificación de las fechas que elegí: 1830-1928, insistía en que la primera hubiera podido ser 1816 ó 1817 debido al Real Decreto de 29 de junio de 1816 por el que Fernando VII creaba el Cuerpo de Médicos de Baños. Desde entonces, los estudios se han centrado sobre la evolución de este Cuerpo. Médicos, historiadores de la Ciencia, han investigado la historia de la hidrología médica en España desde 1816 hasta el periodo más reciente. Pero los trabajos sobre el periodo anterior no parecen haber prosperado tanto. Juan Antonio Rodriguez Sánchez ${ }^{5}$, por ejemplo, considera que:

Pocos conocimientos científicos existían sobre las aguas mineromedicinales españolas a comienzos del siglo XIX. Las singulares obras de Limón Montero, Bedoya o Ayuda (por citar sólo las más ambiciosas y significativas) manifestaban la ingente tarea que habría que realizar para el buen conocimiento de los manantiales y sus aplicaciones terapéuticas. El propio Juan de Dios Ayuda, en atención a esta demanda y como distinción honorífica a su abnegada labor, fue nombrado Subinspector General de las Aguas Minerales de España, cargo con escasas consecuencias en la investigación hidrológica y la institucionalización de la disciplina ${ }^{6}$.

De ahí que J. A. Rodríguez Sánchez atribuya la creación del Real Decreto de 29 de junio a un «arrebato legislativo» que parece no tener antecedentes. Es el aspecto que queremos cuestionar en relación con el/los «campo/s del saber» vinculados a la cura, la medicina y la hidroterapia, tomando como palanca los baños de Trillo conocidos como los baños de Carlos III. El coloquio ofrece la

4 Michel Chadefaud, Aux origines du tourisme dans les Pays de l'Adour, Université de Pau, 1987.

5 Véase por ejemplo Juan Antonio Rodríguez SÁnchez «Institucionalización de la Hidrología Médica en España», en Francisco Maraver Eyzagyuirre (coord.), Establecimientos balnearios, historia, literatura y medicina, Madrid, Universidad complutense, 2006, págs. 25-40.

6 Rodríguez Sánchez, «Institucionalización de la Hidrología Médica en España», pág. 27. 


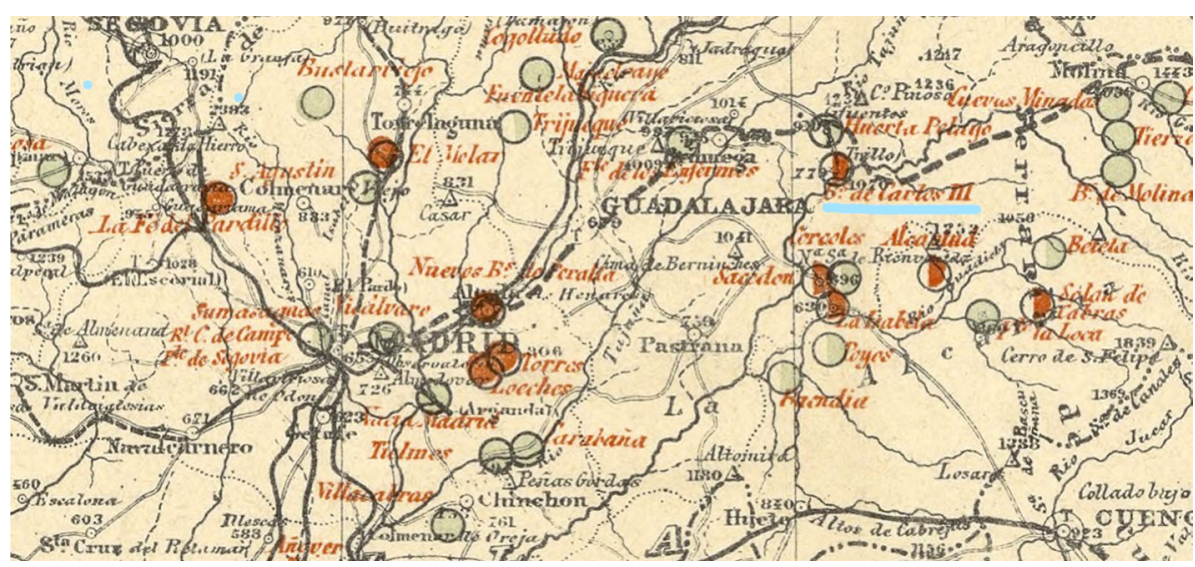

Fig. 1. Mapa de las aguas minerales y termales de España y Portugal. Federico de Botella y de Hornos, inspector de Minas. Hacia [1850]. Fuente: Bibliothèque nationale de France. [Detalle]. https://gallica.bnf.fr/ark:/12148/btv1b53029335j

oportunidad de completar trabajos anteriores y cuestionar las iniciativas que pudieron llevarse a cabo en el último tercio del siglo XVIII y fuesen significativas a la vez porque implicaban un saber médico, una voluntad política y una adhesión de varios sectores de la sociedad. Intentaremos ver por qué esta denominación de «baños de Carlos III», si existen iniciativas reales o del Gobierno al respecto y si son signos de una extensión de la hidroterapia. Nos limitaremos al caso de Trillo que parece anunciar, no con Carlos III pero más tarde, una frecuentación de la Monarquía borbónica de los sitios de la Alcarria cercanos a la Corte. En el mapa de Federico Botella y de Hornos, las aguas de Carlos III (Trillo) aparecen entre los establecimientos de aguas minerales termales y en la categoría de las aguas cloruradas sódicas. Con las fuentes de Sacedón, las de Trillo son las aguas termales más próximas a Madrid.

José Ramón López de los Mozos Jiménez ${ }^{7}$ indica:

No nos son conocidos los orígenes concretos de los Baños de Trillo, pero sí los pasos por que fue atravesando su existencia desde 1770, fecha en que D. Miguel María de Nava, Decano del Consejo de Castilla a la sazón, encuentra mejorada su salud al utilizar las aguas, por entonces remansadas, de la charca del Rey, por lo que de vuelta a la Corte solicita de Carlos III una ayuda económica suficiente como

7 José Ramón López de los Mozos Jiménez, «Caminos a los Reales Baños de Trillo (Guadalajara)», en Manuel Criado del Val (coord.), Actas del II Congreso Internacional de Caminería Hispánica. Tomo I Caminería física, AACHE Ediciones, 1987, págs. 415-422. 
para poder ofrecer dichas salutíferas aguas a todas las gentes. De modo que así se comenzaron a construir los edificios destinados a baños y albergues.

La colección de informes remitidos por los Directores de Baños a partir del decreto de 1816 reúne por suerte documentos anteriores ordenados en el catálogo Balnea ${ }^{8}$. Entre el año de 1770, señalado para Trillo, y 1815, existen documentos valiosísimos y raros, como veremos más adelante, depositados en la biblioteca de la Facultad de Medicina de la Complutense. Permiten evaluar la importancia de los Baños de Trillo en el último tercio del siglo XVIII. Y, por supuesto, después de 1816. La obra ${ }^{9}$ de Alfonso Limón Montero, Espejo cristalino de las aguas de España hermoseado y guarnecido con el Marco de variedad de Fuentes y Baños, cuyas virtudes, excelencias y propiedades se examinan, disputan y acomodan a la salud, provecho y conveniencias de la vida humana, publicada en 1697 permite ver en qué circunstancias aparecen las primeras referencias a las aguas de Trillo.

\begin{tabular}{|c|c|c|c|}
\hline Balneario & año & núm. balneario & signatura \\
\hline Reino de Galicia & 1771 & 2405 & Ca2858(19) \\
\hline Reino de Galicia & 1772 & 2406 & Ca2858(20) \\
\hline Reino de Galicia & 1772 & 2407 & Ca2861G(24) \\
\hline Sacedón & 1784 & 1462 & Ca2861F(25) \\
\hline Trillo & 1785 & 1492 & Ca2797(1) \\
\hline Trillo & 1788 & 1493 & Ca2861H(4) \\
\hline Trillo & 1788 & 1494 & Ca2861H(4) \\
\hline Trillo & 1788 & 1494 & Ca2861H(4) \\
\hline Trillo & 1789 & 1495 & Ca2861H(3) \\
\hline Graena & 1808 & 254 & Ca2858(43) \\
\hline Ledesma & 1815 & 1667 & Ca2861F(1) \\
\hline
\end{tabular}

Fig. 2. Aguas minero-medicinales españolas entre 1771 y 1815 (anteriores al Decreto de 1816). Fuente: Juan Antonio MÉNDEZ APARICIO, Memoria de las aguas minero-medicinales españolas (siglos XIX y Xx), Número 3 extraordinario de Balnea, Publicaciones UCM, 2008

8 Juan Antonio MÉNDEZ Aparicio, Memoria de las aguas minero-medicinales españolas (siglos XIX y XX), Número 3 extraordinario de Balnea, Publicaciones Universidad Complutense de Madrid, 2008.

9 Alfonso Limón Montero, Espejo cristalino de las aguas de España hermoseado y guarnecido con el Marco de variedad de Fuentes y Baños, cuyas virtudes, excelencias y propiedades se examinan, disputan y acomodan a la salud, provecho y conveniencias de la vida humana, Alcalá, Francisco García Fernández, impresor de la Universidad, 1697. https://bvpb.mcu.es/es/consulta/registro.do?id=420072 


\section{Alfonso Limón Montero y la fortuna dichosa}

En 1697, en el prólogo de Espejo cristalino de las aguas de España, Alfonso Limón Montero, alaba las virtudes de las aguas minerales por encima de todos los metales teniendo aquéllas manantiales como éstos yacimientos. Además España tiene multitud de ellas «de gran utilidad, comodidad y regalo». Si los metales, preciosos o no, si las piedras preciosas «ocasionaron a sus habitadores gravísimos daños» por la codicia de los pueblos vecinos, «todo es al contrario en las aguas porque es bien común comunicado sin escasez y poseído sin susto ni envidia y por esta causa sin temor de perderla». Bien supremo que ofrece salud «apenas hay enfermedad que no curen». Y de qué manera más suave. Cuando los otros remedios provocan «desabrimientos y amarguras, dolores y dolencias», «solo las aguas curan los males con descanso, con deleite y contento siendo el bañarse y beber no menos deleitable que provechoso» ${ }^{10}$. Dirigiéndose al lector define un método analítico y afirma ${ }^{11}$ :

[...] era necesario inquirir las virtudes de dichas aguas y para conseguir esto, examinar sus minerales, considerar sus virtudes, y las que podian participar a las aguas, el modo como se las participaban, en que cantidades se mezclaban con ellas, para cuales enfermedades eran útiles, como se avían de usar, con que orden, prevención, y regimiento, en que cantidades, y a que tiempos, y los efectos que causasen en los cuerpos, como le avían de regular y si sobrevenían algunos accidentes como se avían de corregir y enmendar [...]

De paso, no es inútil subrayar la amplitud de miras del autor que manifiesta preocupaciones higienistas y de comodidad: para que «sanos y dolientes tengan en él universal medicina y recreo», añade a los baños de las aguas termales, «los baños de aguas simples de que tantos usan en tiempos calurosos» ${ }^{12}$. Catedrático de vísperas de Medicina en la Universidad de Alcalá de Henares, Limón Montero $^{13}$, en el umbral del siglo XVIII, informa muy temprano sobre las aguas termales de Trillo en una serie de menos de quince fuentes termales ${ }^{14}$ :

\footnotetext{
10 Limón Montero, Espejo cristalino, Prólogo. Del Autor que dexó escrito [pág. 11]

11 Limón Montero, Espejo cristalino, Prólogo. Al lector [pág. 12].

12 Limón Montero, Espejo cristalino, Prólogo. Al lector [pág. 13].

13 Manuel Amezcua, El espejo Cristalino de Limón Montero. Los inicios de la literatura hidrológica en España, Temperamentvm 2009, 10. <http://www.index-f.com/temperamentum/tn10/tfhs01.php>.

14 Limón Montero, Espejo cristalino, Libro II, Tratado I, Capítulo VII, pág. 289. Estas líneas son citadas por Casimiro Ortega en su Tratado de las aguas termales de Trillo, Madrid, Joachin Ibarra, Impresor de Cámara, 1778, pág. 131 en homenaje a Limón Montero y al final del análisis que realizó en circunstancias que más adelante se verán.
} 
Las aguas termales de Trillo se pueden notar entre las más excelentes de España aunque no están en la estimación general que otras, que también a las aguas alcanza la común pensión de las cosas humanas que no solo basta en que tengan prendas para ser estimadas y aplaudidas sino que es necesario tener fortuna dichosa que las aplauda y publique.

Procura preparar los indispensables aplausos «tom[ando] el informe de personas doctas de la Facultad de Medicina que hayan experimentado las facultades de las aguas que se les consulta» y que hayan contestado «el interrogatorio» nominativo. A la sazón menciona al doctor Domingo Estevan Velez, médico de Cifuentes: «hijo de nuestra Ilustrísima Universidad [escribe Limón] y nuestro íntimo amigo y condiscípulo en ella». Si es cierto que la relación personal o sea el factor aleatorio o el interés se revelan primordiales, ya son manifiestos la preocupación por la formación universitaria, el «experimento» y la evaluación personalizada con finalidad legitimadora. De hecho la «relación» que sigue se atribuye al Doctor amigo del autor.

Se describe la situación de Trillo, acceso, vegetación desde las cumbres hasta las orillas del cercano Tajo, nacimiento de las aguas termales cuyas virtudes dependen tanto de su fuerza propia como del suelo que atraviesan y de las plantas que con ellas crecen. Los usos locales testimonian de la calidad de las aguas ya que los labradores cocían en ellas el cáñamo con una eficacia que no había fuera de allí. La observación y «experiencia» de sus efectos permite evaluar cualidades «mineras» de las aguas «que llevadas a otras partes y repuestas pierden mucho de las virtudes con que nacen, si bien no todas, quedándose con algunas aunque en grados remisos». Las aguas se tienen que consumir o usar en el mismo lugar. Se deduce entonces una composición en cualidades primeras dependientes de la proximidad del manantial y en otras «adventicias» que se mantienen con variaciones. Se detalla largamente el nacimiento de las aguas «a golpes», «a la manera que cuando empieza a hervir una caldera». El aire encarcelado se libera «en unas bulas o ampollas, unas grandes, otras pequeñas». Siguen observaciones empíricas muy minuciosas:

[...] suben con impulso de levedad hasta tocar en la superficie donde se quedan formadas por algún tiempo, aunque breve porque como estén compuestas en forma orbicular quedan partes de aire dentro del agua y partes de agua en la región del aire, aquellas levitan y estas gravitan y unas y otras ponen conato natural a tocar a la manera que pueden su centro y por conveniencia de entrambos elementos se hace a uno y a otro conveniente separación deshaciéndose dichos globillos o bulas. 
Las observaciones físicas alternan con las químicas, determinadas primero por la cata del agua con sus tres fases: visual, olfativa, gustativa y con los efectos fisiológicos. Aguas «diáfanas» que saben «un poco a cenagosa a que también tira el olor». Cuando se beben en el mismo baño causan «nauseas y algunas veces vómitos». El doctor se presta a la experimentación para intentar medir la «fuerza» de las aguas e introducir una graduación: «El calor con que nacen es más que tepido y me parece tendrá de intención o radicación como dos grados».

Siguiendo las etapas de su método, la relación evoca, en primera persona ${ }^{15}$, una «experimentación» de la acción de las aguas de Trillo y poniendo «por buen rato ochavos de cobre salieron plateados». Las sortijas de plata «adquieren un color como dorado y las de oro salen como pabonadas». También comprueba que en las aguas embalsadas se forma un depósito de "crasitud bituminosa» y que, por algunos orificios, salen unas aguas «delgadas y sútiles», con más calor, que «mueven sudor y otras evacuaciones». De ahí que se deduzcan los achaques y enfermedades correspondientes a estas aguas: «pasiones de nervios que se ocasionan de causa fría» y «obstrucciones de hypocondrios». De manera más general:

[...] son eficaces contra opilaciones y si hay falta de menstruos en las mugeres ocasionada de ellas, los mueve valerosamente y muchas vezes anticipa el tiempo regular de ellos. Aprovecha a las antiguas levedades de intestinos y también a los largos fluxos de las almorranas de onora y aligera a los pletóricos; acarrea mucha utilidad a los que padecen edemas pertinaces y a los que tienen mal habito de cuerpo, que llamamos cachegia, y a los que padecen llagas antiguas cacoetes los quales sienten singular alivio bañándose y bebiendo dichas aguas.

La relación del Dr. Velez aporta la comprobación de los efectos de las aguas con el caso de la hermana del Conde de Cifuentes, religiosa que padecía, desde la adolescencia, los males del cuadro terapéutico indicado. En vano, tomaba los remedios habituales recetados durante quince años. Con indicación del Dr. Velez empezó en los primeros días de agosto de 1675 una cura de baños termales en Trillo, por mañana y tarde, hasta el 25 del mes, con efectos en la menstruación al cabo de 7 ó 8 días «con anticipación de doze días al tiempo regular». Tenemos así relatados seis casos observados con diferentes achaques y excelentes resultados siendo el último el de un pobre labrador. Las curas son de unos diez a veinte días y no está «experimentado si valen [estas aguas] contra el mal francés».

15 Limón Montero, Espejo cristalino, pág. 291: «Lo que yo tengo experimentado es que [...]». 
Acabada la relación del Dr. Velez, Limón Montero recomienda ampliaciones para la comodidad y precaución médica del baño y medidas de salubridad e higiene. Recomienda también el sistema de divisiones y estanques usado en Sacedón para mayor provecho de las aguas. Utilizando una muestra mandada por Velez, por evaporación y reacciones de las sales obtenidas, determina que en la composición de las aguas entran «betún, azufre, alumbre y salitre». Argumenta su opinión, elemento por elemento, explicando sus manipulaciones. Insiste en la «crasitud» bituminosa, especial en estas aguas, que le parece útil para uso como ungüento en «los afectos de nervios y articulaciones untando con él dichas partes y poniéndolas al sol a que se reseque el dicho lodo y después se quita y limpia» ${ }^{16}$. Y propone varias maneras de usar los principios activos de estas aguas para componer medicinas y curar diferentes achaques.

\section{La insigne labor de Casimiro Ortega}

Esta presentación de las aguas de Trillo y su uso tanto en baños como bebida se va a mantener como referencia en diferentes obras ${ }^{17}$ con algunas variaciones a lo largo del siglo XVIII en particular en el modo de tomarlas. Pero Trillo conoce un destino singular en los años 1770 como lo refiere el Dr. Casimiro Ortega $^{18}$ en su Tratado de las aguas termales de Trillo publicado en 1778. En realidad es tratado en el sentido doble de la palabra ya que la obra trata de manera extensa y docta de las aguas, baños, flora, minerales, instalaciones y lugar de Trillo pero también de la legitimación y por consiguiente de las garantías y hasta protección aportadas por la Facultad, los Consejos y la Corona.

16 Limón Montero, Espejo cristalino, pág. 296.

17 Entre las principales se pueden citar : Josef Mendoza, Virtud medicinal de los baños de la villa de Trillo, 1714; Juan Eugenio del Río, Virtudes medicinales de las aguas termales de la villa de Trillo y método de usarlas, 1741; Juan Gayán y Santoyo, Antorcha methódica, mapa historial, y discursos analyticos, de las aguas termales de la villa de Trillo y método de usarlas, 1741; Juan Gayán y Santoyo, Antorcha methódica, mapa historial, y discursos analyticos, de las admirables termales aguas de los baños de Sacedón, Córcoles, Trillo, [...], 1762; Luis Guarnerio y Allavena, Tratado de las aguas de Trillo, 1777. En su Tratado de las aguas termales de Trillo, Madrid, Joachin Ibarra, Impresor de Cámara, 1778, Casimiro Ortega, págs. 88-89, cita también «un pliego impreso en 1698, que no ha llegado aún a mis manos y se atribuye al Dr. Manuel Porras, [un cuaderno] en cuarto, que salió a luz con instrucciones relativas al uso de varias Aguas que se acostumbran tomar en Madrid y parece dispuesto por el Dr. Eguía u otro Médico de los Reales Hospitales [...] y finalmente un Artículo que insertó el Dr. Casal en el capítulo tercero de su Historia Fisico-Médica del Principado de Asturias, impresa en Madrid en 1762. Como entre todos estos escritos es sin disputa el más apreciable el Tratado del Dr. Limón a quien también por lo general copiaron fielmente los demás en punto de Análisis o escribieron cosas que no merecen impugnarse, me contentaré con hablar de lo que dice aquél célebre Médico [...]»

18 Casimiro Ortega, Tratado de las aguas termales de Trillo, Madrid, Joachin Ibarra, Impresor de Cámara, 1778. 
La posición doctoral de Casimiro Ortega, los cargos asumidos en el momento del Tratado, su elección para efectuar y dirigir las investigaciones sobre Trillo - facetas que iremos desarrollando a continuación - convierten esa obra en un clímax de excelencia de todos los aspectos referidos. El libro consta de cinco capítulos y aspira a la exhaustividad. La lectura del conjunto muestra a cada paso que se ha ido reuniendo todo lo que podía estar relacionado con Trillo y sus baños. La compilación experta es sometida al análisis y a la crítica. Solo comentaremos algunos aspectos.

El esquema es tradicional y el primer capítulo (24 págs.) trata de «la situación de la villa de Trillo, de su antigüedad, lustre, decadencia y estado actual». En el segundo capítulo (28 págs.) tenemos «la situación, descripción, amenidad y producciones naturales de los Baños de la villa de Trillo». El tercer capítulo (92 págs.) es fundamental ya que contiene la Real cédula de S.M. sobre la Análisis de las Aguas de Trillo, y el análisis metódico y minucioso, explicado y detallado de las aguas presentado ante una «Asamblea Médico-Chimica». Siguiendo el esquema establecido por Limón Montero, el capítulo cuarto (60 págs.) reúne 35 observaciones de curaciones y 9 casos que resultaron fatales. El capítulo quinto (11 págs.) retoma los efectos de estas aguas y el método de usarlas. Por fin un apéndice precisa la ruta de Madrid a Trillo reducida de 22 a 16 leguas y organizada en dos jornadas con indicaciones para el hospedaje e información sobre adelantos en la construcción de mesones (uno en Aranzueque y otro en Vélamos de abaxo). En resumidas cuentas, el Dr. Casimiro Ortega prolonga en 1778 la labor emprendida en 1697 por Alfonso Limón Montero dando nuevos vuelos a la dichosa fortuna.

Es notable la descripción original de la situación de los baños en particular la de los edificios. Se impone aquí recordar lo que escribía ${ }^{19}$ a este propósito Limón Montero cuando evocaba las condiciones en las que la hermana del Conde de Cifuentes tomaba los baños:

[...] porque en ellos [los baños] no ay más casa ni más comodidad que una cabaña que se hizo de brozas si bien se vistió por la parte de adentro de tapizes en la mejor forma que se pudo dentro de la qual tenía su cama de colchones y la ropa necesaria para resudar quando salía de ellos.

En la descripción de Casimiro Ortega contamos con varios edificios: los Baños del Rey «en cuya puerta principal se ha colocado el Real Busto de S.M.», el Baño de la Princesa, el Baño de la Condesa, el baño de la Piscina. Existen

19 Limón Montero, Espejo cristalino, pág. 291. 
también «tres cloacas o necesarias» para comodidad de los que tomen las aguas. Estas instalaciones son ampliamente descritas. La distribución de las obras, su solidez y diferenciación en su uso demuestran ya un concepto elaborado de la hidroterapia que ha ido imponiéndose en los 80 años que separan el texto de Limón Montero del de Casimiro Ortega. Los documentos conservados en los archivos confirman esa preocupación por mejorar y ampliar las instalaciones aquí descritas. Se guarda en la biblioteca de la facultad de medicina de la Complutense dos planos de obras de 1788 — sin duda ejemplares únicos— de las reformas que se proyectaron y ¿quizás? ¿sin duda? se llevaron a cabo en los referidos edificios de los baños de Trillo ${ }^{20}$.

Ambos planos proyectan reformas de ampliación de los edificios existentes. Estamos en una fase de expansión. Uno multiplica el número de bañeras, lleva la fecha de junio de 1788 y se le reconoce por el uso de la tinta negra. El segundo es de octubre de 1788 y en él se distinguen las instalaciones existentes marcadas en negro y las ampliaciones que aparecen en color rojo. Las reformas afectan los diferentes edificios e instalaciones ya existentes exceptuando quizás los Baños de la Condesa que pudieran tener un régimen especial. La comparación entre los dos planos deja suponer que el proyecto de junio es más ambicioso que el de octubre y prevé un número más importante de bañeras. Para no multiplicar los documentos que tienen además un tamaño inhabitual nos centramos en los planos de octubre de 1788 pensando que son los más elaborados, sin duda más modestos y puede que el resultado de unos trámites entre el arquitecto y el Consejo de Castilla.

Explicación de las figuras deste Plano

Fig $^{\mathrm{a}} 1^{\mathrm{a}}$ Portal del estado actual y nueba distrib ${ }^{\mathrm{n}}$ con arreglo a la orden del Consejo.

2. Sitio del oratorio y aora escalera princ[ipa $]^{1}$

3. Salas de los enfermos las que se destinan la una para Capilla y la otra para con un enfermo qe aya de estar separado,

4. Pasos para entrar a las oficinas

5. Ofecina para el surtido necesario

6. Cozina

Fig $^{\mathrm{a}} 2^{\mathrm{a}}$. Quarto principal que el Consejo manda sele lebante al ospital

1. Sala para ombres

2. Antesala a recreo

20 Véanse fotos añadidas, fig. 4, 5, 6 signatura Ca 2861 H(4). Balnea núm. 1493, Folio A: Plano de las obras necesarias en los Baños y Hospital de la Villa de Trillo remitido al Consejo por dn Narciso Carrasco Prevendado de la Sta Iglesia de Sig[uen]za y encargado de la direccion y conserbacion de los Baños con representacion de 23 de octubre de 1788. 


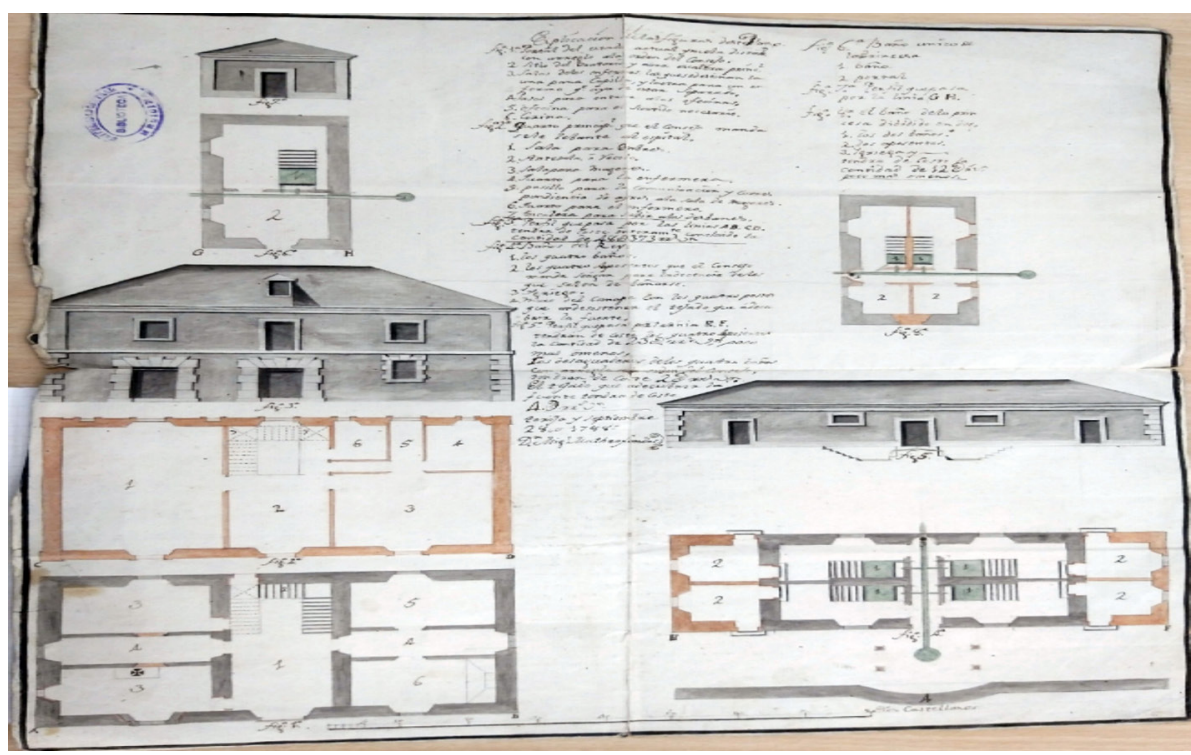

Fig. 3. Plano de las obras necesarias en los Baños y Hospital de la Villa de Trillo [...] octubre de 1788, fuente: Biblioteca de la Facultad de Medicina de Madrid, Ca2861H(4), Balnea núm. 1493

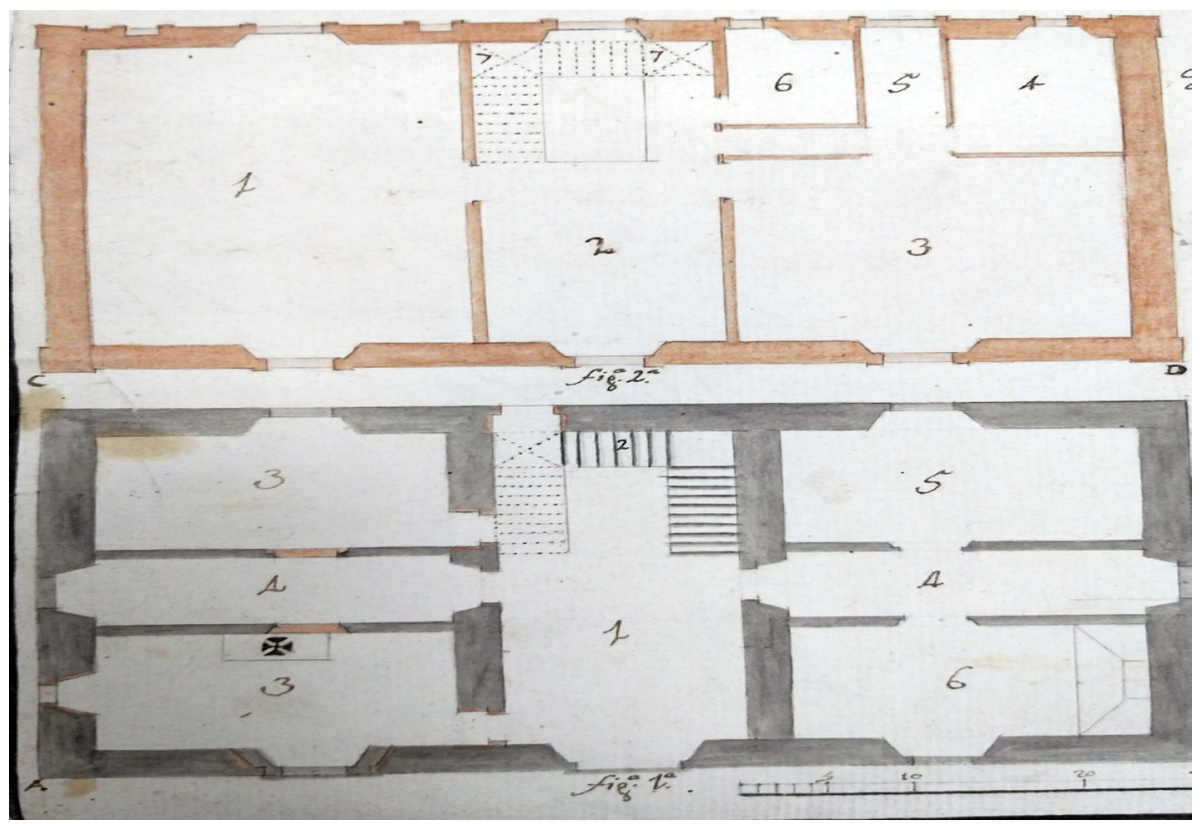

Fig. 4. Baños del Rey. Plano de las obras necesarias. Octubre de 1788, fuente: Biblioteca FMM Ca2861H(4), Balnea núm. 1493 
3. Salapara mugeres

4. Cuarto para la enfermera

5. pasillo para la comunicacion y correspondencia de ayres a la sala de mugeres.

6. Cuarto para el enfermero.

7. Escalera para subir a los desbanes

Tendra de coste enteram ${ }^{\text {te }}$ concluido la cantidad de 48M373 reales de vellon.

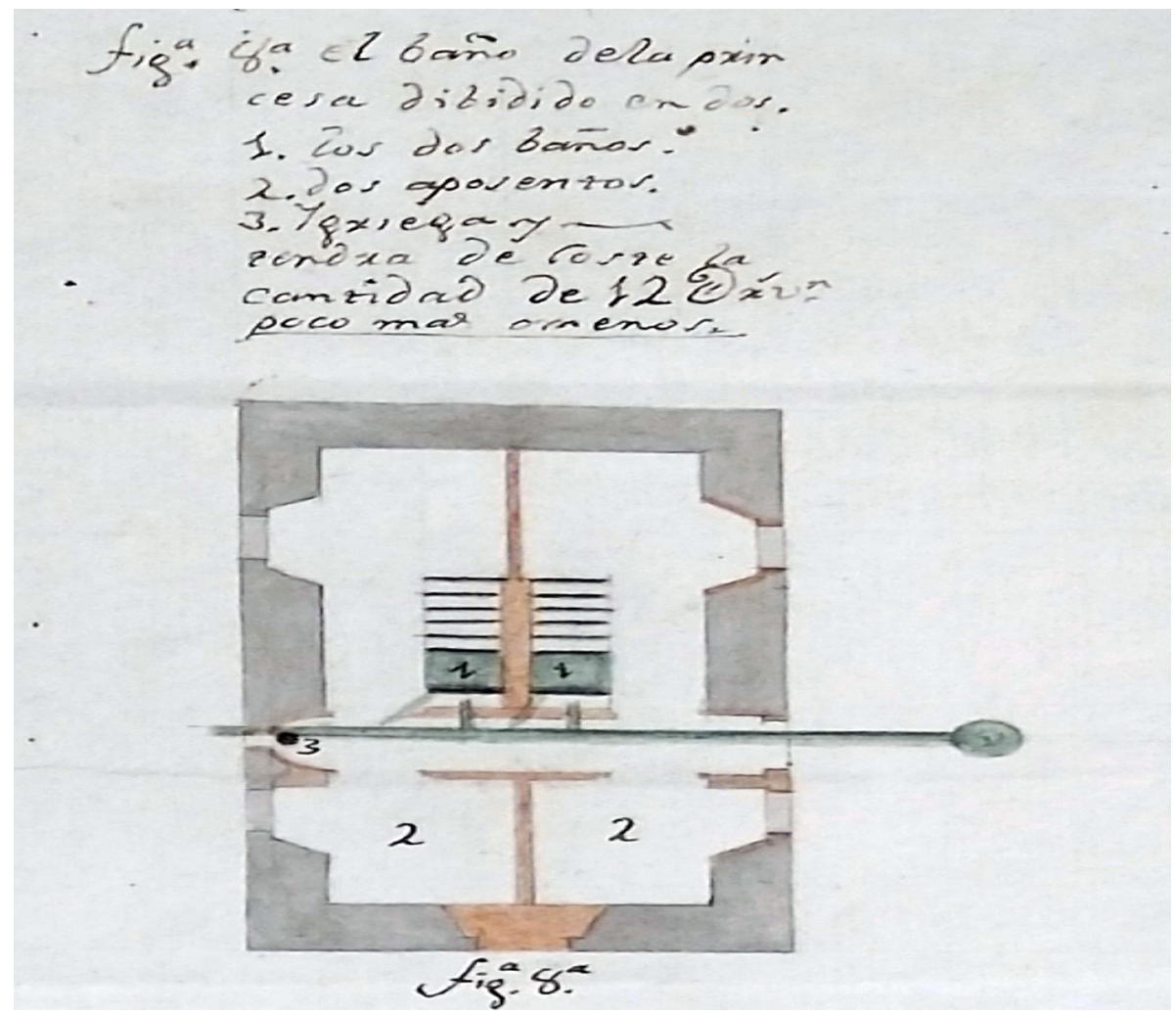

Fig. 5. El baño de la Princesa (fig.8a) dividido en dos $^{21}$. Plano de las obras necesarias. Octubre de 1788, fuente: Biblioteca FMM Ca2861H(4), Balnea núm. 1493

Podríamos seguir con las diferentes partes del proyecto de reformas pero parece que éstas tienen más como finalidad la de aumentar la concurrencia a los Baños que la de añadir conocimientos en el análisis de las aguas y uso de

${ }^{21}$ Explicaciones mencionadas en el plano: «Fig.8a. El baño de la Princesa dividido en dos 1. los dos baños /2. dos aposentos /3. Ygriega /Tendra de coste la cantidad de 12Mrr de vellon poco mas o menos». 
ellas. También parece evidente que, con la creación de aposentos en los Baños del Rey y de la Princesa o la instalación de un tejado para cubrir el baño de la piscina mantenido al aire libre, se busca la comodidad del baño, la higiene, la decencia y la «curiosidad». Pero esto es ya aplicación de las conclusiones contenidas en el Tratado de Casimiro Ortega. Los planos confirman la existencia de instalaciones, su distribución y organización, su coste, la manera con la que se usan los Baños y una serie de elementos concretos y técnicos que aclaran aspectos propios de la época. Hasta el Tratado no existían para Trillo descripciones precisas de los edificios. Los planos las ilustran.

Otro elemento capital del Tratado es la Real Cédula ${ }^{22}$ que explica el papel desempeñado por quienes contribuyeron al desarrollo de los Baños de Trillo y la relación a Carlos III. Lo curioso del caso es que la iniciativa y decisión parecen, de hecho, supeditadas al análisis metódico de las aguas de Trillo, o sea a un proceso científico, y bajo el control de una «Asamblea Médico-Chimica». Veamos el texto con carácter oficial ${ }^{23}$ :

Por quanto el Rey nuestro Señor D. Carlos Tercero (Dios le guarde) a solicitud del Ilustrísimo Sr. D. Miguel María de Nava y Carreño, Caballero del Orden de Calatrava, del Consejo de S.M. y Decano del de Castilla y Cámara, fue servido nombrar al Dr. Casimiro Gomez de Ortega para hacer el examen público y ANÁLISIS metódica de las Aguas Termales de esta villa de Trillo ; determinó S. Ill. ${ }^{\text {ma }}$ que en el día treinta y uno de julio de este año de mil setecientos setenta y siete y en este sitio asignado para celebrar los actos judiciales pertenecientes al común de esta villa y a presencia de su Ayuntamiento, compuesto de los señores Juan Francisco Perez, y Juan Sancho de Elvira, Alcaldes ordinarios, Antonio Sancho y Juan Delgado, Regidores, Juan Sacristan Berzas, Procurador Síndico, y con asistencia de mi el infraescrito Escribano Fiel de fechos, se hiciese la pública Asamblea MédicoChimica y en ella la AnÁlisis de LAS AgUAS termales que se hallan en la jurisdicción de esta villa a cuyo fin el nominado D. Casimiro Gomez Ortega en presencia también del numeroso concurso que por disposición de S. Ill. ${ }^{\mathrm{ma}}$ se hallaba presente para autorizar este acto, leyó la Disertación que comprehende una Certificación de D. Pedro Gutierrez Bueno, individuo del Real Colegio de Boticarios de Madrid, en calidad de Secretario nombrado por S. Ill. ${ }^{\mathrm{ma}}$ para el referido examen y ANÁLISIS que su tenor es el siguiente $[\ldots]$.

22 «Real Cédula de su Magestad sobre la análisis de las Aguas de Trillo» Ortega, Tratado, págs. $57-70$.

23 Ortega, Tratado, pág. 61. 
P. Gutierrez Bueno, boticario aprobado por el Tribunal del Protomedicato, tenía como cometido disipar para todos «las dudas e infundadas opiniones que habían gobernado hasta aquí» ${ }^{24}$ y persuadir de las virtudes de las aguas de Trillo. La personalidad y títulos académicos de Casimiro Gomez Ortega eran un elemento fundamental del dispositivo ${ }^{25}$ :

[...] el Dr. D Casimiro Gomez Ortega, graduado en la Facultad de Medicina por la Universidad de Bolonia, primer Profesor del Real Jardin Botánico de Madrid, Secretario de la Real Academia Médica Matritense para las correspondencias extranjeras, e individuo de las Reales Academias de la Historia de España, Botánica de Florencia, de Ciencias de París y de la Regia Sociedad de Londres [...]

Iniciado el 31 de julio de 1777, el proceso siguió su curso pasando para validación por el Tribunal del Proto-Medicato (10 de octubre) y por último el 11 de abril de 1778, don Antonio Martinez Salazar secretario del Consejo de S.M. firmaba la licencia para la impresión de la Disertación defendida por Casimiro Ortega. Se validaba y publicaba de este modo la Real Cédula sobre el análisis de las Aguas de Trillo.

Por supuesto Casimiro Ortega tuvo que demostrar sus conocimientos y probar que su aplicación a las aguas de Trillo era convincente. La asamblea se componía de facultativos, médicos, cirujanos, farmacéuticos del contorno de Trillo y de otras ciudades. C. Ortega hizo alarde de técnicas esencialmente de física («máquina pneumática, el termómetro, hidroscopio, balanza hidrostática, docismática ${ }^{26}$ ). Insistía en la necesidad de conocer la historia natural y en particular la mineralogía. De hecho la botánica ocupa un espacio significativo y el párrafo IV del capítulo II lista unas 260 plantas que se crían en el sitio de los baños y sus alrededores. De éstas, 96 son medicinales. La noticia de los minerales es más reducida pero alude a colaboraciones y colectas en 1776 en Auteuil con Valmont de Bomare. En esta parte los estudios de referencia son los de Juan Gotschalk Waller[ius], Valmont de Bomare, Plinio. En el discurso de su análisis metódico cita a Herman Boerhaave[n], Stephen Hales, John Woodward, GeorgesLouis Leclerc de Buffon, Juan Gotschalk Wallerius, Antonio Cocchi, Le Roi, Venel, Antoine Grimoald Monnet, Antoine Baumé, Sage, Pierre Joseph Macquer.

El análisis metódico ocupa un lugar destacado. Recoge primero todas las publicaciones sobre las aguas de Trillo desde Limón Montero. Indica que las

\footnotetext{
24 Ortega, Tratado, pág. 66.

25 Ortega, Tratado, pág. 62.

26 Ortega, Tratado, pág. 78.
} 
primeras experiencias se hicieron en 1770 al pie del manantial ${ }^{27}$. Retoma las experiencias de Limón Montero (en realidad, como lo vimos, de Estevan Velez) y rechaza la composición en «salitre, alumbre, azufre, betún». Punto por punto deshace las conclusiones de Velez y en cuanto a la formación de betún, aspecto algo original de estas aguas, la atribuye al desaliño y a la podredumbre lo cual ha sido confirmado con la introducción de medidas de aseo y de cuidado tomadas por Miguel María de Nava. Para emitir un juicio, Ortega realiza cuatro análisis en los cuatro manantiales con el fin de comparar los resultados. Recurre a las técnicas más novedosas y pertinentes. Comprueba el calor utilizando instrumentos de Réaumur y el peso de las aguas con el hidrómetro de Baumé. Para mayor exactitud se sirve de una de «las balanzas docismáticas que hi[zo] construir en París de orden de S.M. para el laboratorio de Chímica que se [iba] a establecer en el nuevo Real Jardín Botánico $[\ldots]^{28}$ ». Para el reconocimiento y separación de las substancias utiliza tres medios experimentales: la observación, la mezcla de reactivos químicos y por fin la evaporación y destilación. El doctor explica ampliamente todas las manipulaciones realizadas y las justifica. Concluye de la manera siguiente ${ }^{29}$ :

[...] participan nuestras Aguas de cinco substancias dos volátiles y tres fixas es a saber de un vapor phlogístico sumamente anodino penetrante y amigo del sistema nervioso, de mediana porción de ayre fixo, de tierra calcárea, de sal común y de sal selenítica. [...] Se ha regulado que de los veinte y cinco granos y medio de principios fixos que corresponde a cada libra ponderal de Agua mineral cerca de catorce granos de sal común, casi tres de sal selenítica y como unos ocho y medio de tierra absorbente, lo que para mayor exactitud figuraremos así: de sal común 13 de grano, de sal selenítica 2 y de tierra absorbente 8 .

Una nota indica que D. Manuel Joachin Enriquez de Paiva, Demostrador Real del Laboratorio de Chimica de Coimbra e Individuo de la Real Academia Médica de Madrid ha encontrado iguales proporciones a partir de un residuo que se le remitió. La comprobación autónoma y distante de las medidas indica que los procesos experimentales se han respetado. Se puede comprobar que la composición realizada por C. Ortega es mucho más precisa, en particular en cuanto a proporciones. Además como rechaza cualquier presencia de azufre, espera que cese el recelo de algunos enfermos y médicos. Recomienda estas

27 Ortega, Tratado, pág. 90.

28 Ortega, Tratado, pág. 104.

29 Ortega, Tratado, pág. 123. 
aguas para «curar úlceras malignas y otros afectos pútridos», «las aguas recién sacadas compiten con la destilada que es la más pura de quantas se conocen» de ahí que puedan penetrar «libremente por los más íntimos recesos del cuerpo humano ${ }^{30}$. La presencia de principios disipables dificulta el transporte de estas aguas en particular en vasijas de barro y se imponen las botellas y frascos bien tapados. Algunas conclusiones ${ }^{31}$ parecen hábiles como por ejemplo:

Que el Agua del Baño de la Princesa es la más virtual o a lo menos la más abundante de phlogisto y así la más adecuada para aquellas enfermedades en que los Médicos juzgan útil la eficacia de este principio. social:

Otras son de una evidencia dudosa $\mathrm{a}^{32}$ e introducen consideraciones de tipo

Por último ha sido casualidad lo que merecía ser efecto de la elección y es el haberse reservado para los pacientes de afectos cutáneos, que por lo regular son los más pobres, el Baño último o sea de la Piscina porque el phlogisto abunda también mucho en sus Aguas [...]

\section{Baños y Hospital}

En efecto parece que se está instalando una ambigüedad en el desarrollo de los Baños. Por una parte se mantiene el cometido hospitalario que se reafirma con nitidez en el reglamento adoptado en 1785 que veremos más adelante. Por otra los Baños evolucionan hacia un concepto de amenidad que ya Limón subrayaba al afirmar que «solo las aguas curan los males con descanso, con deleite y contento siendo el bañarse y beber no menos deleitable que provechoso» ${ }^{33}$. Las conclusiones de Casimiro Ortega también parecen orientarse en ese sentido ya que retoman la opinión de Limón Montero que apuntamos en la nota 14. Insiste en la excelencia de las aguas termales de la villa de Trillo, en las lacras subrayadas por Limón en 1697 como eran la falta de comodidad y la necesidad de ensanchar el espacio del baño ambas cosas sobradamente solucionadas desde entonces por Miguel María de $\mathrm{Nava}^{34}$ :

\footnotetext{
30 Ortega, Tratado, pág. 126.

31 Ortega, Tratado, pág. 129.

32 Ortega, Tratado, pág. 129.

33 Limón Montero, Espejo cristalino, Prólogo. Del Autor que dexó escrito [p. 11].

34 Ortega, Tratado, pág. 133.
} 
[...] convirtiendo los Baños de Trillo por lo cómodo, frondoso y breve del camino desde la Corte a esta villa y desde ella a los Baños por lo delicioso del paseo y por la solidez, comodidad y noble sencillez de los edificios así hechos como proyectados, en un amenísimo sitio de recreo para sanos y enfermos.

Comprobamos pues que a lo largo del siglo XVIII asistimos a un largo proceso de defensa y valoración de las aguas mineromedicinales del que Trillo es un ejemplo entre varios como se podría demostrar a partir del Espejo cristalino. El caso de Trillo es singular por la iniciativa de Miguel María de Nava decano del Consejo y Cámara. El interés del Consejo de Castilla hacia las fuentes hidrominerales es manifiesto. Hubiéramos podido citar otros ejemplos: Sacedón, Solán de Cabras, Graena, Ledesma, Alhama de Aragón, etc. El Consejo mueve los gremios para reformar y mejorar puentes y carreteras con el fin de facilitar el acceso a los baños. Crea establecimientos, adjudica, proyecta las reformas, decide el tamaño, fija el reglamento, financia el conjunto. En el caso de Trillo y en el seno mismo del Consejo aparece la figura de Miguel María de Nava. El Decano del Consejo solía pasar la temporada en Trillo como lo recuerda Jovellanos ${ }^{35}$ :

En Trillo a las nueve: hallamos muy franco y agradable hospedaje en casa de don Narciso Carrasco, prebendado de Sigüenza, que pasa aquí los meses de julio y agosto, por la comisión de cuidar del hospital a cargo del Consejo; ocupa el cuarto bajo y cede francamente el alto. Aquí alojaban el viejo don Miguel María de Nava, los de Ariza y mil señores, que nada importa. Es muy limpia y cómoda casa.

Con Miguel María de Nava se superponen el Decano del Consejo de Castilla y el usuario de los baños de Trillo que venía con su esposa María Jacinta de Lara. Es difícil delimitar el papel del bañista y el del Decano. También es difícil

35 Jovellanos. Cuaderno noveno. Viaje $35 .^{\circ}$. Los Baños de Trillo y retorno al hogar. Real Sitio de San Ildefonso-Madrid-Alcalá de Henares-Aranzueque-Trillo-Aranzueque-Madrid-León-Pajares-Oviedo-Gijón. Día 20 de agosto de 1798 (Gaspar Melchor de Jovellanos, Obras completas, t. viII, Diario 3. ${ }^{\circ}$, ed. de Javier González Santos y María Teresa Caso Machicado, Oviedo, Instituto Feijoo de Estudios del Siglo XVIII / Ayuntamiento de Gijón / KRK ediciones, 2011, págs. 221-223. La cita corresponde a los apuntes del miércoles 22. Jovellanos estuvo en Trillo saliendo de Madrid el 20 de agosto de 1798 y regresando el 13 de septiembre de 1798 (Aranzueque) «[Lunes, 20 de agosto de 1798]. — Exonerado del ministerio de Gracia y Justicia por papel del 15, y despedido el 16 de agosto, volví el 17 a mi casa de Madrid. Estuve en ella el 18 y 19, y el 20, a las cuatro y media de la tarde, salí para Trillo y llegué después de las nueve a Alcalá [de Henares]». La indicación sobre Don Narciso Carrasco es confirmada por los archivos (AHN y Medicina UCM véase plano de Torija septiembre 28 de 1788 Dn Migl Matheo fondos) así como es interesante la alusión a Miguel María de Nava (1703-1783). En 1798 había fallecido desde hacía 15 años pero su recuerdo se mantenía cuando Jovellanos estuvo en Trillo. 
saber si el Decano actúa en Trillo como iniciador de un modelo que el Consejo aspira a difundir o si su iniciativa es el resultado de una forma de favoritismo o si estamos ante una pareja agradecida que, recobrada la salud, quiere hacer obra de caridad ayudando a los pobres del Hospital. Los documentos oficiales definen al Decano del Consejo como «juez protector». Es una función oficial que existe en varios Baños y Miguel María de Nava es sustituido en este cargo en 1784. Se mantienen estos cargos hasta la disolución del Consejo en 1833. De todas formas, en el caso de Miguel María de Nava y de su esposa, María Jacinta de Lara, se plantea la cuestión de la financiación del Hospital de Trillo. Tras la disolución del Consejo de Castilla en 1833, una serie de recopilaciones administrativas de archivos posteriores a 1817 refieren la tramitación en el Consejo de Castilla de documentos que explican la financiación del balneario desde la época de Miguel María de Nava y de su mujer María Jacinta de Lara ${ }^{36}$. El «juez protector» de los Baños y su esposa habían adquirido acciones en el Banco de San Carlos para costear el Hospital de Trillo que incluía, por lo menos, parte de los Baños. Jovellanos ${ }^{37}$ menciona este acuerdo:

Hay tres casitas de baños: la primera y tercera tienen dos cada una; la segunda, cuatro, en sus ángulos; más adelante, una con un solo baño, que llaman de La Leprosa, solo aprovechado por algún otro doliente de erupciones cutáneas. Un pobre y mal dotado hospital: solo tiene el rédito de 40.000 reales en acciones

36 AHN, Leg. 2958 núm. 1. «Rafael Paz y Fuentes Madrid 30 de junio de 1834 al Presidente del Supremo Tribunal. Exmo Sr. Según he hecho indicación al extinguido Consejo de Castilla [acciones] cuyo protector había comprado existen en mi poder 2949 reales de los dividendos de las acciones que en el suprimido Banco de San Carlos havían impuesto los fundadores del Hospital que hay en dicho Trillo qe lo fueron el Excmo S. Miguel María de Nava y su mujer la Sra Da María Jacinta de Lara y dicha cantidad es en efectivo deducido el importe de algunos muebles qe se han comprado pa los expresados baños y hospital, reparos y otros gastos; conservando por separado en papel con qe se han pagado aseos de dichos dividendos: un cuadro qe se dice de deuda consiente al cinco por ciento negociable núm. 3876 qe suena de veinte mil r. vellones, otro de deuda sin interes por x.n. 3495 r. y 30 ms núm. 22509. Otro también de renta perpetua (al cinco por ciento) annual núm. 2833 y otro [insulado] extracto de inscripción pr acción inalienable de quatro acciones a qe han quedado reducidas pr el Banco Español de San Fernando y a consecuencia de Rs Ordenes las impuestas en el Nacional de Sn Carlos por los expresados fundadores pa el citado Hospital de Trillo. Y además en poder de aquel Cura Parroco encargado de su administración, 4110 r. según su última cuenta de la temporada del año anterior qe poco hace me ha sido remitida qe aguardaba pa su entrega por la extinción del Consejo de Castilla se me prebiniese lo qe se subiese ponconducense [?]; siendo dicha cantidad lo liquido, satisfechos empleados, alimento de los pobres del Hospital y varios reparos en este y los baños qe se han ido mejorando en lo posible y según lo permitía el sobrante de los productos de aquel establecimiento qe vpre he dejado en poder del parroco por su abono. Y deseando hacer entrega de las citadas existencias de dinero y papel asi como de la indicada última cuenta espero qe VE se sirva tener la bondad de señalarme la persona aquien deba realizarla. Dios gue a VE ms as. Madrid 30 de junio de 1834.»

37 Jovellanos, Cuaderno noveno. Viaje 35. Los Baños de Trillo. La cita corresponde a los apuntes del jueves 23 . 
del Banco [de San Carlos], dejados por el ilustrísimo [Miguel María de] Nava y su mujer. Los Baños: 400 ducados que da el bañero que los lleva en arriendo y cobra de los que entran los derechos, arreglados por arancel. Veré si puedo recoger un impreso para escribir menos.

Pero la relación de Jovellanos aporta otro testimonio. Sus indicaciones confirman esa ambigüedad antes señalada de la presencia de «pacientes de afectos cutáneos, que por lo regular son los más pobres» (Casimiro Ortega) que se concentran en el Baño de la Piscina que, por lo que refiere Jovellanos, se ha convertido en el Baño de «La Leprosa solo aprovechado por algún que otro doliente de erupciones cutáneas». Como muchos otros en la época, los Baños de Trillo cumplían el cometido de acoger a enfermos sea cual sea su condición social.

El reglamento adoptado en 1785 en Trillo lo indica claramente ${ }^{38}$ : «Artículos que para el buen gobierno de los baños de Trillo acordó el Consejo en 8 de junio de 1785; los que se observarán por todos los concurrentes». El artículo primero es una declaración de principios, generosa y liberal: «Toda persona, de cualquier condición que sea, podrá tomar, sin contribución, y preferencia alguna, el Agua que necesite para su uso, sea en vasos, o en cántaros, sea en la Villa, o en los Baños». Sin embargo el artículo segundo introduce un matiz de paz civil y orden («Para evitar disputas, y observar el orden que corresponde»), una distribución en tres clases y una contribución económica. La primera clase pide una reserva «y por esta preferencia pagará cada persona ocho reales por cada Baño». La segunda clase tiene que apuntarse en una lista cada mañana «desde el amanecer» y esperar su turno. El coste es de cuatro reales. Esta obligación explica que los bañistas se levanten antes de que amanezca para estar presentes antes que los demás. Lo confirman los Diarios y cartas. Por fin está la tercera clase :

En la tercera clase serán comprehendidos los notoriamente pobres, o que por su estado se conceptúen tales (como los Religiosos Mendicantes), todos los cuales entrarán en los baños desocupados sin perjudicar en manera alguna a los contribuyentes ; pero si a los de esta tercera clase se les siguiese algún perjuicio de esperar a que concluyan de bañarse los contribuyentes, podrán entonces acudir a los Baños llamados de la Piscina, que están destinados para los pobres, cuyas puertas encontrarán francas a cualquier hora [...].

38 AHN, Consejos 2958-2959. Artículos que para el buen gobierno de los baños de Trillo acordó el Consejo en 8 de junio de 1785; los que se observarán por todos los concurrentes. 


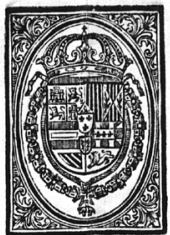

\section{A R T ICULOS,}

QUE PARA EL BUEN GOBIERNO DE LOS BAÑOS DE TRILLO acordó el Consejo en 8 de Junio de 1785 ; los que se observarán por todos

los concurrentes.

I. Oda persona, de qualquiera condicion que sea, podrá tomar, sin contribucion, y preferencia alguna, el Agua que necesite para su uso, sea en vasos, ó en cántaros, sea en la Villa, ó en los Baños.

II. Para evitar disputas, y observar el órden que corresponde, se establecen tres clases. Los de la primera (deseando bañarse) han de tener eleccion, y preferencia al Baño que mas les acomode, ñalando hora, para que el Bañero lo tenga desocupado; pero no podrán los tales impedir que otros se bañen 1 hom $\mathscr{f}^{2}$ antes, ó despues de la hora señalada ; y por esta preferencia |pagará cada persona ocho reales por cada

III. Los de la segunda clase, luego que se presenten en los Baños, acudirán al Bañero, para que éste los, saño: ponga en la Lista, que ha de formar segun se vayan presentando en el distrito de los Baños, que será desde el , sifalita amanecer, y no antes. Igualmente ninguno podrá solicitar se le ponga en Lista con antelacion de un dia para ia lasemáa otro, á fin de ganar la antigüedad, ni el Bañero podrá hacerlo, sin que el Pretendiente se halle actualmente eníla, picala

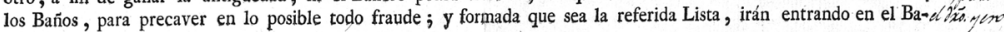
ńo por su órden.

IV. La tho:

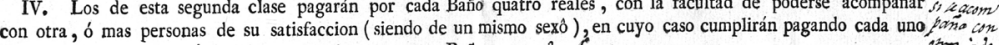
dos reales, sean dos, ó mas los que se junten en un Baño, fon caiva hoxa.

V. En la tercera clase serán comprehendidos los notoriámente pobres, ó que por su estado se conceptúen ta- Ma Mlos les (con en los Baños que se hallen desocupados, sin per- Who fo

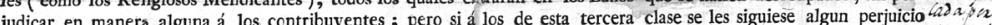
judicar en manera alguna á los contribuyentes; pero si a los de esta tercera clase se les siguiese algun perjuicio as a de esperar á que concluyan de bañarse los contribuyentes, podrán entonces acudir á los Baños llamados de la Pis- 0 na 200 cina, que están destinados para los pobres, cuyas puertas encontrarán francas á qualquiera hora, previniendo á los de esta clase, que mediante que los Baños son tan espaciosos, que en el que menos caben quatro personas, deberán entrar acompañados de otras personas de su sexô, y satisfaccion, para no hacer mala obra á los demás, especialmente quando el concurso es grande : y para obviar disturbios, el Bañero formará igual Lista que á los de segunda clase.

VI. Para cortar los desórdenes que puedan ocurrir, se ha de observar por todos los concurrentes, y que se hallasen en la comprehension de los Baños, y su camino regular desde la Villa, entera sujecion, y sumision á las providencias de la Justicia Ordinaria, y Bañero, que inmediatamente ha de permanecer desde el amanecer hasta el anochecer en el sitio de los manantiales, sin que se permitan contenciosos recursos por escrito, ó de palabra, guardándose por todos la debida harmonía : y para evitar escándalos, se previene al Bañero, cuide de que los asistentes que hayan de entrar al quarto del Baño con el enfermo sean de un mismo sexô , á no ser que concurra la circunstancia de ser un matrimonio, madre, ó hija del enfermo, ó persona de ninguna sospecha.

VII. Los que sacasen cargas de Agua para conducir á Madrid, ó á otros Lugares, pagarán por cada carga ma yor, que se entiende de seís cántaros, quatro reales, y si fuesen vidrios, 10 mismo; y así á proporcion por las cargas menores, y medias, y por un cántaro, por grande que sea, veinte y dos maravedís.

VIII. Los Carruages de quatro ruedas, ó Coches, prgarán por cada dia dos reales, y los de dos ruedas real y medio ; y ningun Cochero , y Calesero podra impedir la entrada de otro Coche, ó Calesa que posteriormente llegase, permitiéndolo el buque de la Cochera.

\section{O B L IGACIONES DEL BANERR.}

1. Que todo el año ha de celar para que no se hagan perjuicios, ni daños á los edificios, y árboles de los Baños, dando parte á la Justicia , ó Comisionado, de qualquiera que notare, para su castigo, y remedio ; y que esta misma obligacion se exíja por la Justicia anualmente al Guarda del Monte al tiempo que se le toma el Juramento acostumbrado.

II. Que el mismo Bañero ha de cuidar por todo el año de que los Baños, y sus Oficinas estén con la limpiea correspondiente, avisando al Comisionado de qualquiera gotera, ú otro dańo que advierta.

III. Que igualmente ha de celar, que los enfermeros tengan aseada la Casa-Hospital, dando noticia á la Justicia, ó Comisionado de qualquiera desórden que notase entre los enfermeros, ó concurrentes en el tiempo que se usa el Hospital, para su remedio.

$$
2458 \%
$$

Fuente: A.H.N. Consejos 2958-2959. Artículos que para el buen gobierno de los baños de Trillo acordó el Consejo en 8 de junio de 1785; los que se observarán por todos los concurrentes 
Dicho sea con humor, para la tercera clase el reglamento es muy liberal ya que tienen libre acceso a lo que no está ocupado y a los Baños de la Piscina, aquellos que Jovellanos denomina de La Leprosa. Si se mira en los planos de 1788, se puede comprobar que la Piscina se encuentra al aire libre con un muro de delimitación denominado «canapé» y que el proyecto propone la construcción de un tejado sobre pilares para proteger la bañera. Casimiro Ortega ${ }^{39}$ indica que «el phlogisto abunda también mucho en sus Aguas que serán más copiosas y virtuales si se recoge todo el caudal de que hay indicios según está ya providenciado.» $\mathrm{O}$ sea que la capacidad del baño de la piscina podría aumentar si se revelase necesario por razones diversas. Evidentemente nace una contradicción entre las aspiraciones a una mayor amenidad para los Baños y el cometido hospitalario y curativo. La variable económica se anuncia ya como el elemento separador.

Para concluir vemos que el caso de los Baños de Trillo permite seguir cierta evolución de la hidroterapia en España a lo largo del siglo XVIII. Para estas fuentes tenemos dos textos fundamentales que son El Espejo de Limón Montero y el Tratado de Casimiro Ortega que distan de unos 80 años. El primero lanza las fuentes de Trillo según un proceso conocido en otros puntos y harto estudiado por M. Chadefaud en los Pirineos franceses. En el umbral del siglo XVIII se manifiesta una conjunción de miras, por lo menos, entre los Condes de Cifuentes y el doctor Domingo Estevan Velez, médico de Cifuentes y condiscípulo nada menos que de Limón Montero. Este tiene la inteligencia, viveza, formación y cultura que le permiten abrir nuevos derroteros desde su cátedra de vísperas de la Universidad de Alcalá. La orientación es magistral y Limón Montero ha sentido los nuevos aires. Dejando fábulas, mitos y creencias adhiere a la experimentación, la desarrolla y aplica de manera brillante. No importa que él y el doctor Velez se equivoquen en sus conclusiones, el método permitirá las necesarias correcciones y adaptaciones. Es lo que, más tarde, lleva a cabo Casimiro Ortega que reconoce en Limón un fabuloso precursor. Ortega tiene una de las formaciones más avanzadas de España y se codea con sus homólogos de otras capitales. Sus referencias demuestran un conocimiento de lo más pertinente de su(s) disciplina(s) y de su arte. Y no le falta habilidad. Incluso política. Su Tratado es indiscutible porque abre la posibilidad de debates, constantemente y en todos sus aspectos. Busca el consenso. Su saber en hidrología mineral es de lo más avanzado que se conoce pero, por naturaleza, tiene sus límites y se nota que Casimiro Ortega lo sabe y se pronuncia con habilidad y prudencia. Por razones que, al fin y al cabo tienen poco interés, adhiere al proyecto de consolidar la

39 ORTEga, Tratado, pág. 130. 
reputación de los Baños de Trillo y añade sus aplausos a los de Velez y Limón para seducir la fortuna dichosa, si no, para bien de todos, por cierto, no para mal. Ya lo dijo Limón en su Prólogo: «apenas hay enfermedad que no curen» las aguas. Y tan suavemente. De modo que se forja la unión del político y del sabio que Michel Foucault ${ }^{40}$ ha estudiado, en particular para el tratamiento de la locura. El caso de Trillo manifiesta también una voluntad de mejorar una situación sobre la base de una voluntad política unida a conocimientos científicos o pre-científicos y a autoridades académicas reconocidas.

Por cierto el mismo C. Ortega señala la crisis en la que se ha sumido Trillo durante la guerra de sucesión ${ }^{41}$. Velez defendía los baños en un contexto de crecimiento y prosperidad de Trillo, C. Ortega los defiende con la voluntad de provocar un nuevo despegue. Acompaña los pasos de Miguel María de Nava que, con toda sinceridad y pasión, parece unir sus deseos y afectos privados con su voluntad de difundir el bien y ayudar. El papel del Decano del Consejo es evidente y aparece constantemente. Con su esposa María Jacinta de Lara se enlaza una relación especial que engloba las estancias en Trillo. Faltan elementos sobre María Jacinta de Lara. Parece fallecer en 1784 pero su fecha de nacimiento es incierta. La pareja no tuvo descendencia y no aparecen, en ningún momento, aspiraciones al lucro sino más bien asistencia al Hospital de Trillo con las donaciones referidas. Por lo visto hay una historia privada. Pero sobretodo está la figura del «juez protector» asumida por Miguel María de Nava. En el caso de Trillo la obtención definitiva de la Cédula ${ }^{42}$ el 11 de abril de 1778 legitima, a mi parecer, la denominación de Baños de Carlos III. El proceso emprendido por M. María de Nava apuntaba a este fin y la publicación del Tratado de C. Ortega lo deja patente. Lo cual no significa una relación de Carlos III con Trillo comparable a la de Fernando VII con la Isabela. Pero pone de realce una manera de gobernar en la que un personaje con cargos significativos se encuentra misionado para controlar un proyecto validado por los Consejos. Trillo no es un caso único si bien es único el desenlace obtenido con la adopción de la Cédula. La existencia de un «juez protector» o de una figura similar no significa que se cree un «Real Sitio». Pero de cierto modo, este sistema de una figura designada

40 Michel Foucault, Folie et déraison. Histoire de la folie à l'âge classique, Paris, Plon, [1961] o Histoire de la folie à l'âge classique. Folie et déraison, Paris, Gallimard, 1972. Pero también Naissance de la clinique. Une archéologie du regard médical, Paris, P.U.F, 1963 y Surveiller et punir. Naissance de la prison, Paris, Gallimard, 1975.

41 OrTega, Tratado, pág. 18: «La opulencia y lustre que gozaba esta villa con aumento de su población y fundaciones que dexaron sus vecinos en el siglo pasado se desvaneció con motivo de las guerras de sucesión a principios de este siglo. Desde 30 de noviembre de 1710 estuvieron aloxados por siete días en Trillo 1400 soldados Ingleses a quienes hubo que contribuir con todo lo necesario [...]»

42 Ortega, Tratado, pág. 146. 
para buena marcha de una iniciativa prepara, por sus ventajas y sus límites, el Real Decreto de 29 de junio de 1816 por el que Fernando VII creaba el Cuerpo de Médicos de Baños. En relación con los campos del saber, el caso de Trillo, como otros similares que se podrían estudiar, aporta nuevos conocimientos en la administración y gestión de este tipo de actividades que cuentan con sectores complejos y múltiples.

No insistiremos en los cambios aportados desde el punto de las mentalidades. Un comentario de la estancia de Jovellanos en Trillo entre el 20 de agosto y el 13 de septiembre de 1798 permitiría analizar una nueva actividad (o actividad reactivada) como la de los bañistas y agüistas, sus modalidades, la vida social generada, las nuevas formas de viajar por temporadas con sesiones de 20 días dictadas por la cura médica. También la aparición o el desarrollo de relatos adaptados como el Diario y la narración en $1^{\text {a }}$ persona así como nuevos usos receptivos, nuevos modelos: baños, paseos, encuentros de temporada, etc. Un relato subjetivo que abre al lector la intimidad de la salud del autor con temas muy personales que cuestionan la decencia y el pudor. Más allá de Jovellanos, el lenguaje médico permite la descripción más o menos ofensiva de cuestiones estéticas, digestivas, cutáneas, sexuales, de ciclo, de procreación. Se instaura una nueva relación de cada uno con su cuerpo, su intimidad, su salud y, en cadena, con la de los demás. Cada vez más, cada uno se convierte en médico de sí mismo y un poco de los demás, abriendo nuevas paletas de sensaciones, de relaciones personales que se intercambian durante los paseos, las visitas, los baños, el consumo de agua. Esta agua que se convierte en elemento complejo relacionado con la salud, la higiene, la pureza y el comercio. Se toma, se ofrece, se comparte, se envasija, se embotella, se transporta, se vende y se compra. No sólo en España sino en todos los países occidentales donde en algunos puntos de la geografía pasa como en Trillo ${ }^{43}$ :

[...] si se añade la agradable compañía de los Bañistas que concurren de la Corte y de otras partes, más bien que un albergue de achacosos parece Trillo en aquella estación un sitio de recreo para sanos y enfermos.

Para cerrar todavía más el círculo indicar que nos parece que queda clara la singularidad de los baños de Carlos III en Trillo. No lo son porque sean únicos ya que Limón Montero abre el siglo XVIII con unos 12 baños referenciados y unas 30 fuentes y hacia 1850, el Dr. Rubio estima que España cuenta con 232 manantiales, 705 fuentes de las que 355 no son utilizadas. Como lo vimos, Li-

43 Ortega, Tratado, pág. 25. 
món Montero «lanza» los baños de Trillo y Rubio coloca la fuente de Carlos III (Trillo) en séptimo puesto ${ }^{44}$ por el número de agüistas (1258) justo después de La Isabela (1405). El siglo XVIII conoce una fuerte extensión de las fuentes y baños hidrominerales y en 80 años la fortuna convierte la fuente de Trillo en fuente de Carlos III sin que el monarca haya pisado el sitio. Circunstancias personales de Miguel María de Nava, Decano del Consejo de Castilla favorecieron el desarrollo del sitio con un cuidado del que testimonian los planos, por lo visto hoy únicos, encontrados en la biblioteca de la Facultad de Medicina de Madrid. El Real Decreto de 29 de junio de 1816 tuvo entonces antecedentes pero no bajo la forma elegida por Fernando VII. Los baños de Carlos III muestran una voluntad política de desarrollo de la hidroterapia legitimada por los avances de los conocimientos en mineralogía, botánica, química y en medicina aplicados a las fuentes mineromedicinales. En Trillo, Casimiro Ortega experimenta con sumo rigor y publica los resultados en 1778 bajo la forma del Tratado de las aguas termales de Trillo que se premia y valida con Real Cédula de Carlos III. Con el tiempo, este proceso pudo encontrar ciertas limitaciones que el Real Decreto intentaría sobrepasar impulsando una nueva dinámica. A finales del XVIII, a esta extensión y aplicación de conocimientos, se unen intereses locales, nuevas sensibilidades, preocupaciones por la salud, atracción hacia cierto tipo de vida social y una estética renovada. Esas inclinaciones no se limitan a España. Gustos similares se dan en otros países de Europa occidental en torno al agua y sus virtudes. Estas vienen relacionadas con la utilidad, comodidad y regalo y pueden «cura[r] los males con descanso, con deleite y contento». Por poco que, en un momento determinado, el discurso médico incluya el agua de mar, entonces la afición se amplia. De ahí que, en esos momentos, las aguas sean capaces de mover a la gente, de lanzarla por caminos y rutas, de sugerirle estancias, programas curativos, rituales y si viene a fallar o a debilitarse el motivo de la salud quedan la comodidad y regalo, el descanso, deleite y contento. Otros motivos de viajar.

44 Rubio, Tratado completo, p. 605. 